Check for updates

London

Cite this as: $B M J$ 2021;373:n923 http://dx.doi.org/10.1136/bmj.n923 Published: 07 April 2021

\section{Covid-19: Hospital admissions and deaths could rise this summer, modellers warn}

\author{
Ingrid Torjesen
}

The later stages of the UK government's roadmap out of lockdown are "highly likely" to cause a surge of covid-19 infections, hospital admissions, and deaths this summer, suggests modelling from three groups of scientists considered by the Scientific Advisory Group for Emergencies (Sage).

SPI-M-O, Sage's Scientific Pandemic Influenza Group on Modelling (Operational) subgroup, reviewed modelling from Imperial College London, the University of Warwick, and the London School of Hygiene and Tropical Medicine. It concluded that any resurgence in hospital admissions and deaths after reopening non-essential retail, hairdressers, gyms, and outdoor hospitality from 12 April was "highly unlikely to put unsustainable pressure on the NHS." $1-4$

But the return of indoor socialising, the reopening of indoor hospitality including cinemas, theatres, and concert halls (stage 3) from 17 May, and the removal of remaining social distancing rules with full unlocking (stage 4) from 21 June "is highly likely" to lead to a further resurgence in admissions and deaths, says the SPI-M-O paper. The scale, shape, and timing of that potential third wave is "highly uncertain," it adds.

In most scenarios modelled, the third wave is anticipated to be smaller than the second wave seen in January 2021, with a peak occurring in summer or autumn. But the most pessimistic scenarios, modelled by scientists at the London School of Hygiene and Tropical Medicine, predict admissions and deaths of a similar scale to January 2021.

\section{Modelling}

Scientists at the London School of Hygiene and Tropical Medicine assumed higher virus transmission after all restrictions are lifted and used lower but plausible vaccine efficacy. They assumed that the AstraZeneca vaccine would reduce transmission by only $31 \%$, while the teams at Imperial College London and the University of Warwick based their calculations on 50-75\% reduced transmission.

The modelling from the University of Warwick suggested that most deaths and hospital admissions in a post-roadmap third wave would involve people who had received two vaccine doses, even without vaccine protection waning or a new variant that escapes vaccines. High levels of uptake in the age groups most at risk would mean that immunisation failures accounted for more serious illness than unvaccinated people, the team said.

The models assume that the effectiveness of vaccines remains high and immunity does not wane, and they do not consider the impact of new variants of concern, against which existing vaccines may be less effective.

The $\mathrm{R}$ rate in England is currently estimated to be o.8-1.0, up from 0.6-0.8 before schools reopened. It is too early for the estimated $\mathrm{R}$ rate to fully reflect the impact of schools reopening or lockdown easing at the end of March, says SPI-M-O, which is not confident that R now remains below 1 in any NHS England region.

As lockdown measures are eased further under the roadmap the $\mathrm{R}$ rate is expected to rise substantially, and scientists at Imperial College London suggest that it could exceed 4 when restrictions are fully lifted from the end of June. As there is considerable uncertainty about the level of control that can be achieved at each step of the roadmap, SPI-M-O says that it remains critically important to evaluate the effect of each step before taking the next.

The government seems likely to come under pressure from Sage to maintain some social distancing measures after 21 June, even if only as guidance. SPI-M-O says, "Maintaining baseline measures to reduce transmission once restrictions are lifted is almost certain to save many lives and minimise the threat to hospital capacity."

\footnotetext{
Scientific Advisory Group for Emergencies. Imperial College London: evaluating England's roadmap out of lockdown, 30 March 2021. 5 Apr 2021. https://www.gov.uk/government/publications/imperial-college-londonevaluating-englands-roadmap-out-of-lockdown-30-march-2021.

2 Scientific Advisory Group for Emergencies. University of Warwick: road map scenarios and sensitivity, 29 March 2021. 5 Apr 2021.

https://www.gov.uk/government/publications/university-of-warwick-roadmap-scenarios-and-sensitivity-29-march-2021.

3 Scientific Advisory Group for Emergencies. LSHTM: interim roadmap assessment: prior to Step 2, 31 March 2021. 5 Apr 2021.

https:/www.gov.uk/government/publications/lshtm-interim-roadmap-assessment-prior-to-step-2-31-march-2021.

4 Scientific Advisory Group for Emergencies. SPI-M-O: Summary of further modelling of easing restrictions-Roadmap Step 2, 31 March 2021. 5 Apr 2021. https://www.gov.uk/government/publications/spi-m-o-summary-offurther-modelling-of-easing-restrictions-roadmap-step-2-31-march-2021.

This article is made freely available for use in accordance with BMJ's website terms and conditions for the duration of the covid-19 pandemic or until otherwise determined by BMJ. You may use, download and print the article for any lawful, non-commercial purpose (including text and data mining) provided that all copyright notices and trade marks are retained.
} 